\title{
SENSITIVITY OF UPPER OCEAN DYNAMICS IN HIGH-RESOLUTION TROPICAL INDIAN OCEAN MODEL TO DIFFERENT FLUX PARAMETERIZATION: CASE STUDY FOR THE BAY OF BENGAL (BOB)
}

\author{
Subrat Kumar Mallick ${ }^{1 *}$, Neeraj Agarwal ${ }^{1}$, Rashmi Sharma ${ }^{1}$, K.V.S.R. Prasad ${ }^{2}$ \\ ${ }^{1}$ OSD/AOSG/EPSA, Space Applications Centre, ISRO, Ahmedabad -edu.subrat@gmail.com, \\ (subrat, neeraj, rashmi)@sac.isro.gov.in \\ ${ }^{2}$ Dept. of Met. \& Physical Oceanography, Andhra University, Visakhapatnam - prasadkvsr@yahoo.com
}

Commission V, SS: Atmosphere, Ocean, Weather and Climate

KEY WORDS: Air-sea interface, Exchange coefficients, Flux parameterization, Latent heat flux, Ocean General Circulation Models (OGCMs), Relative wind, Stability function, Transfer coefficient, Tropical Indian Ocean (TIO)

\begin{abstract}
:
Simulation experiments using a high-resolution ocean general circulation model (OGCM) of the tropical Indian Ocean (TIO) were carried out to assess the model's sensitivity to different flux parameterization. The flux formulation proposed by Kara et al. (2000) is used in the control run (CR). One more experiment differing in the bulk fluxes formulation for the computation of momentum, freshwater and heat is carried out. In the first experiment (CR), actual wind is used for the computation of the exchange coefficient in air-sea bulk flux formulation. In the second experiment (E1), model surface current is used in the wind stress formulation to compute the turbulent air-sea fluxes for TIO region. The formulation used in E1 is the same as it is used in CR, instead of actual wind, relative wind component is used in flux formulas. Both experiments are carried out for the period 2014-2016. The OGCM is forced using the daily fields of winds, radiation and freshwater fluxes obtained from ERA-Interim Reanalysis. In this study, we examine and quantify the performance of the above-mentioned experiments with respect to observations from ARGO, satellite-based sea surface temperature (SST) and sea surface salinity (SSS) for the year 2015. We observe that the upper ocean dynamics is significantly modulated by different flux algorithms. The errors in simulated SST is reduced by $\sim 8 \%$ to $10 \%$ in E1 compared to CR, respectively. The temperature errors in the top $20 \mathrm{~m}$ depth are reduced by $8 \%$ in E1. It is found that this flux formulation using relative winds is effective in accurately simulating the upper ocean dynamics in strong wind regimes of the Bay of Bengal.
\end{abstract}

\section{INTRODUCTION}

Momentum and heat flux exchange at the air-sea interface constitute key connector between the ocean and atmosphere and play a significant role in the circulation and the energy exchange between these two systems (Gill, 1982; Fairall et al., 1994, 1996a, 1996b, 2003; Kara et al., 2000; Siedler et al., 2013). In ocean general circulation models (OGCMs), surface wind stress and the heat fluxes are the major driving forces that modify the upper ocean dynamics and thermodynamics (Yuen et al., 1992; Chen et al., 1994; Shriver and Hurlburt, 1997; Swenson and Hansen, 1999; Kara et al., 2000). Therefore, both momentum and heat fluxes are essential for turbulent mixing in the upper ocean (Barnier, 1998).

In OGCM simulations, turbulent air-sea fluxes (TASFs) are generally implemented either one of the three ways: i) using a prescribed fields that are generated from a climatological data set (da Silva et al., 1994), atmospheric model (Kallberg, 1998), and remotely sensed and field (like satellite and buoy) observations (Cumming et al., 1997; Weller et al., 1998); ii) using bulk parametrizations that depend on the surface characteristic at the air-sea interface (e.g., heat fluxes (Hogan and Rosmond, 1991); and iii) using turbulence-based air-sea bulk flux formulations (Fairall et al., 1996a, 1996b, 2003). The first method is exclusively used for OGCM simulations, where a gridded field of surface wind stress and heat fluxes are interpolated to the model grid at each time step. Other two methods are generally used in OGCMs, where the essential atmospheric properties are supplied through a prescribed field or some other sources such as available meteorological surface state parameters, and a bulk transfer coefficient (Brodeau et al., 2017).

The benefit of using prescribed fields is the assurance of accurate forcing and computationally it is less expensive for the OGCM simulations. The major drawback of using prescribed fields prevent the cyclic feedback mechanisms between the coupled ocean-atmosphere system. This limitation allows the model and bulk formulas to determine the TASFs at each time integrating step of the OGCM simulation (Kara et al., 2000). McCreary et al. (1993) suggested that using model SST in the computation of surface fluxes of an OGCM simulation automatically provides a physically realistic tendency toward the correct SST simulation, that avoid model SST to drift. Therefore, the accurate notation of bulk formulation for the computation of TASFs is more important when performing large-scale OGCM simulations for the tropical oceans (Atlas, 1987; Atlas et al., 1987; Price et al., 1987) and the good knowledge of TASFs boosts the performance and the longevity of OGCM.

In general practice, the magnitude of ocean surface currents is at least one order smaller with respect to $10 \mathrm{~m}$ wind and assumed to have a negligible effect on TASFs. A number of recent experimental studies have examined with this

\footnotetext{
${ }^{*}$ Corresponding author
} 
approximation and found that ocean surface currents in the wind stress formulation can minimize a positive bias in the ocean dynamics (Luo et al., 2005; Duhaut and Straub, 2006; Dawe and Thompson 2006; Zhai and Greatbatch, 2007; Hughes and Wilson 2008; Scott and Xu, 2009; Zhai et al., 2012; Munday and Zhai, 2015) and the effect is so-called relative wind-stress effect). Pacanowski (1987) and Luo et al. (2005) have shown that the relative wind-stress effect in a revised wind-stress formulation reduces the strength of equatorial current (by $\sim 30 \%$ ) to a more realistic level, which has direct impact on sea surface temperature (SST) and the upper ocean dynamics, thereby improving the model simulations of the tropical ocean. Zhai and Greatbatch (2007) reduction in the magnitude when they included ocean surface currents in the wind-stress formulation. The relative windstress effect brings relatively a small change in the wind-stress magnitude and heat flux by about $\sim 2 \%$ when averaged over the North Pacific, it systematically reduces the magnitude of ocean surface currents, particularly in high oceanic wind zone (Zhai and Greatbatch, 2007; Eden and Dietze, 2009; Munday and Zhai, 2015; Xu et al., 2016). Duhaut and Straub (2006), Zhai and Greatbatch (2007), and Xu and Scott (2008) reported a significant reduction on the wind energy input by revised wind-stress formulation and also a damping effect on the eddy kinetic energy (EKE) by about $\sim 10 \%$ by eddy/wind interaction in their northwestern Atlantic simulation. Eden and Dietze (2009) and Rath et al. (2013) quantify a similar amount of reduction in EKE in the sub-polar region. In the tropical region, the reduction is much higher (i.e., $\sim 50 \%$ ) or even more.

In comparison, there have been numerous modelling studies using bulk aerodynamic algorithm for the calculation of TASFs, accounting for the realistic simulation of the dynamics and thermodynamics of couple GCMs with better accuracy and ease of computation (Zeng et al., 1998; Kara et al., 2000; Shinoda et al., 2013; Chen et al., 2015; Jensen et al., 2016, 2018). Therefore, ocean surface currents and SST have significant impact on the parametrization of bulk formulas (Dawe and Thompson, 2006; Munday and Zhai, 2015; Brodeau et al., 2017). Since direct measurements of TASFs are difficult, unpredictable and highly sensitive to small variations in the physical condition of the medium, they cannot be used to build global or regional climatologies of TASFs (Brunke et al., 2003, 2011; Brodeau et al., 2017). Rather, this information gives reasonable facts before the development and improvement of bulk air-sea flux parameterizations (Fairall et al., 1996b, 2003, 2011; Edson et al., 2013). In a $0.20^{0}$ North Pacific regional model, Dawe and Thompson (2006) found estimate of input forcing to the ocean and drive the upper and Rath et al. (2013) reported a similar mechanism of

that including model surface currents in the bulk formulas actually reduces heat fluxes by about $\sim 10 \%$ in the Kuroshio region, although the basin averaged heat flux reduction is quite small (i.e., 1\%-2\%). Interestingly, the reverse effect was observed in the tropical Pacific region where the heat fluxes increase because of surface warming that brings changes in the surface dynamics. Dawe and Thompson (2006) further suggested that changes in surface turbulent heat fluxes due to ocean surface currents in the bulk formulation may result from not only the direct effect of including ocean surface currents in the heat flux computation but also the indirect effect of including ocean surface currents in the wind stress computation, that modulate SST and hence surface heat fluxes via ocean dynamics. However, the relative importance of the direct and indirect effect are still uncommon and unpredictable.

Differences in the state-of-the-art bulk algorithms have been repeatedly shown to lead to a relatively large spread in the computed TASFs (Blanc,, 1985, 1986, 1987; Zeng et al., 1998; Eymard et al., 1999; Brunke et al., 2002, 2003). In spite of this, we ignore large uncertainties in meteorological surface state variables from different sources (Josey et al., 1999, 2014; Berry and Kent, 2005), which has now become a common practice to neglect the accuracy of various constants and parameter approximations used in bulk formulas. On the other hand, the uncertainties associated with these conditions and assumptions are not properly diagnosed to constitute actionable information for concerned users.

So far, the focus of previous studies on this topic has been primarily to quantify the performance of coupled GCM, and to some extent, on Tropical Ocean using air-sea bulk flux algorithm. There have been few studies reporting the sensitivity of the boundary layer dynamics of the coupled system to TASFs flux algorithm. Furthermore, the previous studies often rely on the sensitivity of North Pacific, North Atlantic and the Southern Ocean model simulations [e.g., Dawe and Thompson, 2006; Zhai and Greatbatch, 2007; Eden and Dietze, 2009; Munday and Zhai, 2015] to bulk flux algorithm. Here we investigate for the first time the sensitivity of upper ocean dynamics to different bulk flux algorithm in the Bay of Bengal. With this concern in mind, we examine and quantify the performance of the dynamics of upper ocean simulation to different bulk flux algorithm with relative wind effect using high-resolution (i.e., $0.10^{\circ}$ ) stand-alone Tropical Indian Ocean model.

The paper is organized as follows. Section 2 provides a brief description of input forcing and validation data sets. Section 3

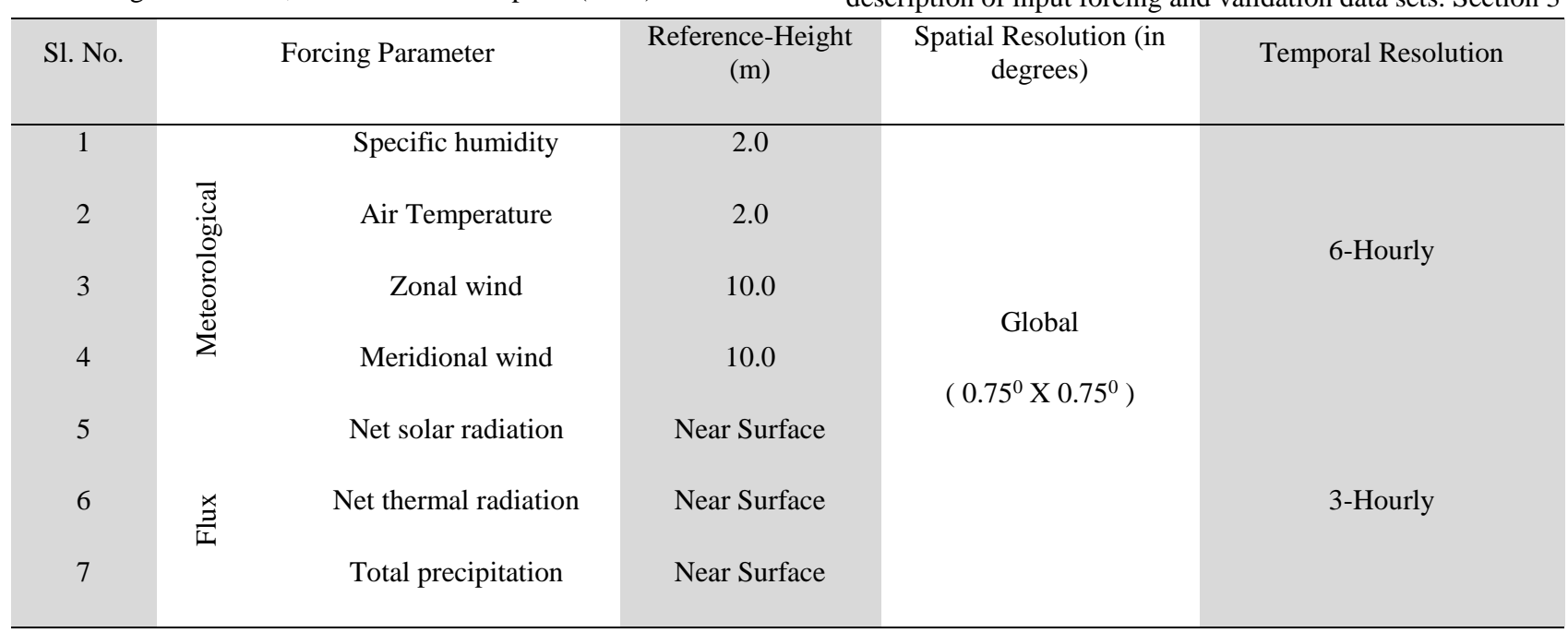

Table 1: ERA-Interim Forcing field

This contribution has been peer-reviewed. 
provides a brief model description and experiment design. Section 4 discusses the results and important findings. Section 5 concludes with a brief summary of our results.

\section{DATA USED}

\subsection{Forcing Data}

Table 1 summarizes atmospheric flux data from the European Centre for Medium-Range Weather Forecasting (ECMWF) Interim Reanalysis (ERA-Interim) that have been used to force the model. ERA-Interim analyzed fields of specific humidity and air temperature at $2 \mathrm{~m}$ height, zonal $(\mathrm{u})$ and meridional $(\mathrm{v})$ wind component at $10 \mathrm{~m}$ height, mean sea level pressure; and forecast field (Dee et al., 2011) of surface net solar radiation, surface net thermal radiation, and precipitation at a spatial resolution of $\sim 80 \mathrm{~km}$ (T255 spectral) are used as forcing. These surface meteorological variables (e.g., Specific humidity, air temperature, zonal an meridional wind) are available at 6-hourly (from 00 Coordinated Universal Time (UTC)) interval, while the surface fluxes are available at an interval of 3-hours (from 00 UTC). The details of the input meteorological variables and fluxes can be found in Erik Anderson (version 1.2, 2011).

\subsection{Data for Validations}

\subsubsection{Satellite Data}

A daily product of $\mathrm{Kd} \_490 \mathrm{~nm}$ prepared from the merged (MERIS, MODIS Aqua, SeaWiFS and VIIRS) fully normalized remote sensing reflectance products at 443, 490, 555 and $670 \mathrm{~nm}$ using the semi-analytical method of Lee and Arnone (2005). Kd_490nm is available from GlobColour through the HERMES web interface. In this study, we have used Level-3 (L3) products of regular spatial resolution of $4 \mathrm{~km}$. The merged data product is available at 8-day intervals (ftp://hermes.acri.fr/?class=archive). The merged data had gaps which were filled by making a daily climatological dataset for the global domain.

A daily product of the Group for High-Resolution Sea Surface Temperature (GHRSST) data incorporate SST observations from various available sources like microwave and infra-red sensors. The Level-4 (L4) product is generated using various objective analysis techniques to produce gap-free SST maps over the global oceans. In this study, we have used L4 GHRSST product with a regular spatial resolution of $1 \mathrm{~km}$ (Donlon et al., 2014). The data was downloaded from the Physical Oceanography Distributed Active Archive Center (PODAAC) (https://podaac.jpl.nasa.gov/GHRSST).

Monthly climatology of river runoff for Ganga-Brahmaputra derived from altimeter observations (Papa et al., 2010) has been used in the model.

\subsubsection{In-situ Data}

The Coriolis Ocean Dataset for Re-Analysis (CORA) product is a global dataset of in-situ temperature and salinity measurements. The CORA observations come from different sources collected by the Coriolis Data Centre in collaboration with the In-Situ Thematic Centre of the Copernicus Marine Service (CMEMS). This dataset is revised every year by the R\&D Coriolis team, and data are extracted in the NetCDF Argo format at a given date. The dataset contains data from different types of instruments: mainly Argo floats, Expendable Bathythermographs (XBT), Conductivity-Temperature-Depth (CTD) and eXpendable-Conductivity-Temperature-Depth (XCTD) profilers, and moorings (Cabanes et al., 2013). The data set is available on a monthly basis. In order to re-initialize the OGCM a monthly climatology of temperature and salinity was generated using the CORA dataset from $2006-2012$.

In order to validate model subsurface parameters, in-situ measurements of temperature and salinity profiles were used. These datasets were obtained from the National Oceanographic Data Center (NODC) under the Global Temperature and Salinity Profile Program (GTSPP) that provides temperature and salinity profile data. These data are compiled from several in-situ platforms including XBTs, CTDs, drifters, ARGO floats (Sun et al., 2010). The data are available from Ocean Archive System (OAS) (ftp://ftp.nodc.noaa.gov/pub/gtspp/indian/).

\section{OCEAN MODEL AND EXPERIMENTS DESIGN}

\subsection{Model Description}

The model used in this study is based on the Modular Ocean Model (MOM, version 3.0) (Pacanowski and Griffies, 1999). This is a primitive equation, a hydrostatic model with a free surface. For this study, the model is configured for the Indian Ocean $\left(27^{0} \mathrm{E}-142^{\circ} \mathrm{E}, 35^{\circ} \mathrm{S}-26^{0} \mathrm{~N}\right)$ with a variable horizontal resolution that it is uniform $0.1^{0} \times 0.1^{0}$ in the region $55^{\circ} \mathrm{E}-100^{\circ} \mathrm{E}$ and $10^{\circ} \mathrm{S}-23^{\circ} \mathrm{N}$ and reaches a minimum up to $1.0^{\circ}$ in the rest of the domain. It has $50 \mathrm{z}$ levels in the vertical grid (vertical resolution ranging from $2.5 \mathrm{~m}$ at the surface to $5320 \mathrm{~m}$ at the bottom, with top 14 levels in the upper $36 \mathrm{~m}$, shown in Table-3). The model uses the Arakawa B-grid and leapfrog scheme for numerical simulations which makes it easy to solve the momentum equations and the well mixed, weakly stratified layer. The vertical mixing based on nonlocal K-profile parameterization (Large et al., 1994) known as KPP mixing scheme has been used. Bathymetry data are taken from ETOPO-2. (Data Announcement 88MGG-02, Digital relief of the Surface of the Earth, NOAA, National Geophysical Data Center, Boulder, Colorado, 1988).

Using climatological temperature and salinity from Levitus (1982) and CORA dataset (as discussed in section 2.2.2), the model was re-initialized (Balmaseda et al., 2007), and spun up from rest and forced with ERA-Interim daily analyzed wind fields, air temperature, specific humidity, net solar and thermal radiation to obtain the initial condition for 2014. The daily climatology of diffused attenuation coefficient (Kd_490; as discussed in section 2.2.1) was used to determine the penetrative depth of blue-green component of solar radiation in the model. The penetrative depth of shortwave radiation is exponentially computed using shortwave parameterization scheme. The detail description of shortwave parameterization is mentioned in section 3.2 (Paulson and Simpson, 1977). Kd_490 varies with space and time, depending upon the nutrient-rich active zone and biogenic sediment deposits in different regions. The other attenuation parameter like $\mathrm{R}$ is then determined from Jerlov (1968) look-up table, including the use of $0.35 \mathrm{~m}$ for $\zeta 1$ in prescribing the absorption of the red light. Monthly climatology of altimeter derived river discharge data from Ganga, Brahmaputra (Papa et al., 2010) was used in the model. Runoff discharge from other prominent rivers that flow into BoB (Irrawaddy, Damodar and Godavari) has been taken from Vorosmarty et al. (1998). The river 
discharge is distributed horizontally around the exact river mouth locations in the first model layer. The model was then further integrated from 2014 until December 2016. This base experiment is referred to as a control run (CR).

\begin{tabular}{|c|c|c|c|c|c|c|}
\hline Exp & Model & $\begin{array}{c}\text { Model } \\
\text { Domain }\end{array}$ & $\begin{array}{c}\text { Spatial } \\
\text { Resolution }\end{array}$ & Forcing Field & Runoff Data & Parameterization \\
\hline $\mathrm{CR}$ & MOM V3.0 & $\begin{array}{l}\mathrm{IO}\left(27^{0} \mathrm{E} \text { to }\right. \\
142^{0} \mathrm{E} \text { and } \\
34^{0} \mathrm{~S} \text { to } \\
\left.26^{0} \mathrm{~N}\right)\end{array}$ & $\begin{array}{l}1 / 10^{\circ} \text { in the } \\
\text { Indian Ocean } \\
\& \text { gradually } \\
\text { decreasing to } \\
1^{\circ} \text { elsewhere }\end{array}$ & $\begin{array}{l}\text { Specific humidity, } 2 \mathrm{~m} \\
\text { air temperature, } 10 \mathrm{~m} \mathrm{U} \\
\& \mathrm{~V} \text { component, total } \\
\text { precipitation, surface } \\
\text { net solar and surface } \\
\text { net thermal radiation }\end{array}$ & $\begin{array}{l}\text { Ganges, } \\
\text { Brahmaputra, } \\
\text { Irrawaddy, } \\
\text { Damodar and } \\
\text { Godavari }\end{array}$ & $\begin{array}{l}\text { Spatially varying } \\
\text { diffused attenuation } \\
\text { coefficient }\left(\mathrm{Kd}_{4} 490\right) \text { in } \\
\text { the upper ocean } \\
\text { (Paulson and Simpson, } \\
1977) \text {. } \\
\& \\
\text { Kara et al., } 2000\end{array}$ \\
\hline E1 & Same as CR & Same as CR & Same as CR & Same as CR & Same as CR & $\begin{array}{l}\text { Same as CR } \\
\& \\
\text { Relative Wind Stress } \\
\text { Effect (Dawe and } \\
\text { Thompson, 2006) }\end{array}$ \\
\hline
\end{tabular}

Table 2: Configurations name and setting used for sensitivity tests and experiments.

\begin{tabular}{|c|c|c|c|c|c|c|c|c|c|}
\hline Levels & Depth (m) & Levels & Depth (m) & Levels & Depth (m) & Levels & Depth (m) & Levels & Depth (m) \\
\hline 1 & 1.000 & 11 & 25.520 & 21 & 119.370 & 31 & 363.720 & 41 & 1583.400 \\
\hline 2 & 3.020 & 12 & 28.500 & 22 & 135.370 & 32 & 423.720 & 42 & 1870.000 \\
\hline 3 & 5.080 & 13 & 31.500 & 23 & 152.610 & 33 & 496.090 & 43 & 2170.000 \\
\hline 4 & 7.230 & 14 & 35.820 & 24 & 170.960 & 34 & 579.600 & 44 & 2481.420 \\
\hline 5 & 9.480 & 15 & 43.320 & 25 & 190.200 & 35 & 671.960 & 45 & 2825.350 \\
\hline 6 & 11.850 & 16 & 54.000 & 26 & 210.000 & 36 & 770.000 & 46 & 3217.950 \\
\hline 7 & 14.350 & 17 & 66.000 & 27 & 230.000 & 37 & 870.000 & 47 & 3667.950 \\
\hline 8 & 16.980 & 18 & 78.200 & 28 & 251.960 & 38 & 983.400 & 48 & 4175.350 \\
\hline 9 & 19.730 & 19 & 90.960 & 29 & 279.600 & 39 & 1133.400 & 49 & 4731.420 \\
\hline 10 & 22.580 & 20 & 104.610 & 30 & 316.090 & 40 & 1333.400 & 50 & 5320.000 \\
\hline
\end{tabular}

Table 3: Vertical discretization of the water column in our model.

\subsection{Numerical Experiments}

To investigate the sensitivity of upper ocean dynamics using TIO model to different flux parameterization, we performed a sensitive experiments E1 with reference to control run (CR). The details description of these experiment set up is mentioned in Table 2. In the first experiment (CR), the daily climatology of $\mathrm{Kd}$ _490nm (as discussed in section 2.2.1) and $10 \mathrm{~m}$ atmospheric wind are considered for the simulation. In CR, the actual wind component is used for the computation of the exchange coefficient in the bulk flux formulation. In the second experiment (E1), the exchange coefficients are computed based on the relative wind effect on air-sea bulk flux formulation proposed by Dawe and Thompson (2006) (Eq. 1). The bulk flux formulation used in CR and E1 is well wellknown Kara et al. (2000) algorithm. Both CR and E1 are .

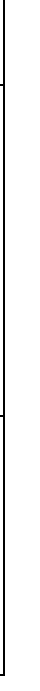

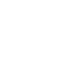


transfer or exchange coefficients for wind stress $\tau, \boldsymbol{U}_{10}$ is the $10 \mathrm{~m}$ atmospheric wind, $\boldsymbol{U}_{s}$ is the model surface current, $T_{a}$ is $2 \mathrm{~m}$ air temperature, $T_{s}$ is model surface temperature (or model $\mathrm{SST}), q_{a}$ is the specific humidity of $2 \mathrm{~m}$ air, $q_{s}$ is the saturated humidity at SST, sensible heat $Q_{s}$, and latent heat $Q_{l}$, respectively, $\boldsymbol{U}_{10}-\boldsymbol{U}_{s}$ is the relative wind (wind velocity at reference (i.e., $10 \mathrm{~m}$ ) height with respect to the first depth level of model surface velocity), $T_{a}-T_{s}$ and $q_{a}-q_{s}$ are the differences in potential temperature and humidity between the atmosphere, and the ocean surface (first depth level of OGCM), respectively, and heat flux $(Q)$ is positive for the warmer ocean. Equation (1) states that the surface momentum and turbulent air-sea heat fluxes (TASFs) depends on the relative wind component. Different bulk formulae's, proposed by climate modeler's (Large and Pond, 1982; Zhang and McFarlane, 1995; Zeng et al., 1998; Fairall et al., 1994, 1996a, 1996b, 2003), differ mainly in the methods used to compute the transfer coefficients (like, $C_{d}, C_{h}$ and $C_{e}$ ) that vary with the magnitude and physical condition of the atmospheric boundary layer (Dawe and Thompson, 2006).

\subsection{Shortwave Parameterization Scheme}

The subsurface heating parameterization used here was proposed by Paulson and Simpson (1977). It is represented as:

$$
I_{z}=I_{0}\left[R e^{-z / \zeta_{1}}+(1-R) e^{-z / \zeta_{2}}\right]
$$

where $\mathbf{I}_{\mathbf{z}}$ is the downward irradiance $\mathbf{I}_{\mathbf{0}}$ is the incident irradiance, $\zeta_{1}$ and $\zeta_{2}$ are attenuation lengths for blue-green and red light respectively and $\mathrm{R}$ is an empirical constant. Diffused attenuation coefficient usually kept vertically constant but spatially vary with water types Jerlov (1976). Depending on the wave-length and biogenic components of the water, Jerlov classifies the oceanic water types into five types. Generally, the water types are classified as Jerlov I, IA, IB, II and III. Type 1(Jerlov I) represents clear water in open ocean type $\mathrm{V}$ (Jerlov III) is high turbid water.

The value of $\mathrm{R}$ is taken to be 0.58 and that of $\zeta_{1}$ and $\zeta_{2}$ is $0.35 \mathrm{~m}$ and $23 \mathrm{~m}$ for type I (Jerlov I) waters respectively. The divergence of downward irradiance may be depicted as:

$$
D I V_{(p e n)}=\frac{\partial I}{\partial z}
$$

this is added to the source term as

$$
S_{c}=\operatorname{Source}+S_{q s w} * D I V_{(p e n)}
$$

where $\boldsymbol{S}_{\boldsymbol{q} \boldsymbol{s}}$ is the ocean surface net shortwave radiation, this is then finally added to the tracer equation

$$
\frac{\partial T}{\partial t}=-U . \nabla T+A_{h}\left[\nabla_{x}^{2} T+\nabla_{y}^{2} T\right]+A_{z} \nabla_{z}^{2} T+S_{c}(5)
$$

where $\mathbf{U}, \boldsymbol{S}_{\boldsymbol{c}}, \boldsymbol{A}_{\boldsymbol{h}}$ and $\boldsymbol{A}_{\boldsymbol{z}}$ are the ocean currents, source term, horizontal and vertical eddy diffusivity, respectively. The lefthand side of (5) is the local temperature gradient and on the right-hand side of (5), the first, second, third and fourth terms are characterized as the advection, turbulent, diffusion and the source terms.

\section{RESULTS AND DISCUSSION}

\subsection{Momentum Flux Differences between the CR and E1}

Including ocean model surface current in the bulk formulas leads to a slight but wide-spread weakening of the mean surface wind stress (Figure 1). This weakening in surface wind stress is maximum in those regions where ocean surface currents are relatively strong. For example, the strength of the mean wind stress averaged over the South-West $\mathrm{BoB}$ near the Southern tip of Srilanka region $\left(5^{0}-8^{0} \mathrm{~N}, 80^{\circ} \mathrm{E}-86^{\circ} \mathrm{E}\right)$ is about $~ 8 \%$ to $12 \%$ weaker in $\mathrm{E} 1$ than in $\mathrm{CR}$, in agreement with the 5\%-10\% difference reported by Dawe and Thompson (2006). Similar percentage decreases are also found in the East India Coastal region is about $\sim 6 \%$ to $8 \%$. When averaged over the $\mathrm{BoB}\left(5^{0}-25^{0} \mathrm{~N}, 78^{0} \mathrm{E}-100^{\circ} \mathrm{E}\right)$, the mean wind stress in $\mathrm{E} 1$ is about almost $4 \%$ weaker than those in CR.

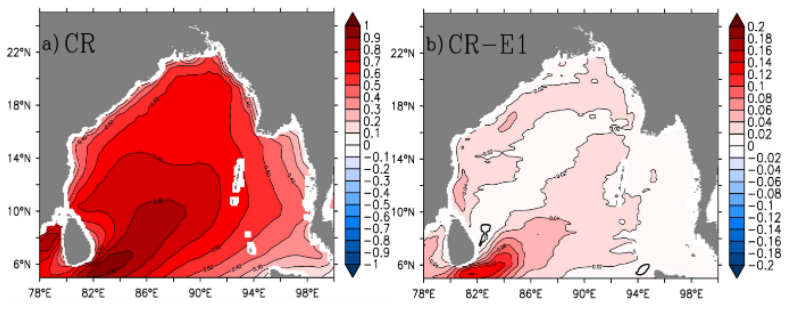

Figure 1. Magnitude of time-mean surface wind stress

(dyn/cm2) of (a) CR and differences in the magnitude of the time-mean between (b) CR and E1 for the year 2015

\subsection{Heat Flux Differences between the CR and E1}

Figure 2 shows the time-mean (or annual average) net surface heat flux averaged over the year 2015 in CR and the differences between the E1. Although the overall patterns of the mean surface heat fluxes in E1 experiments are very similar, including ocean surface currents in air-sea flux calculations lead to a significant reduction in surface heat loss in the eastern and western basin of $\mathrm{BoB}$ region. Whereas in the central $\mathrm{BoB}$ it is increased by $\sim 10-14 \%$. When averaged over the $\mathrm{BoB}\left(5^{0}-25^{0} \mathrm{~N}, 78^{0} \mathrm{E}-100^{\circ} \mathrm{E}\right)$, the mean heat flux in $\mathrm{E} 1$ is about almost $\sim 6 \%$ higher than those in CR.

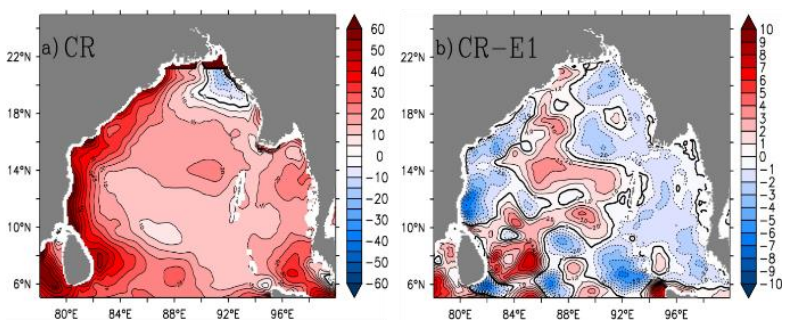

Figure 2. Time-mean Heat flux (Watt/m2) of (a) CR and the time-mean differences between (b) CR and E1 for the year 2015

Interestingly, figure 2(b) makes it clear that the differences in surface heat flux between CR and E1 are not a direct effect of including ocean surface currents in the turbulent heat flux calculations, but mainly an indirect effect of including ocean surface currents in the wind stress calculation via surface current differences between the two experiments Dawe and Thompson (2006). Differences in surface heat flux between CR and E1 are closely linked to their SST differences (Figure 
3). The pronounced heat flux differences in the entire $\mathrm{BoB}$ region and the western boundary current regions are in opposite phase to the SST differences, that shows changes in SST is one of the primary contricontributor which modulate surface heat fluxes in the basin. This further infers the SST differences between $\mathrm{CR}$ and $\mathrm{E} 1$, especially in the coastal region, due to wind stress differences (Figure 1) induced by relative wind in the flux formulation.

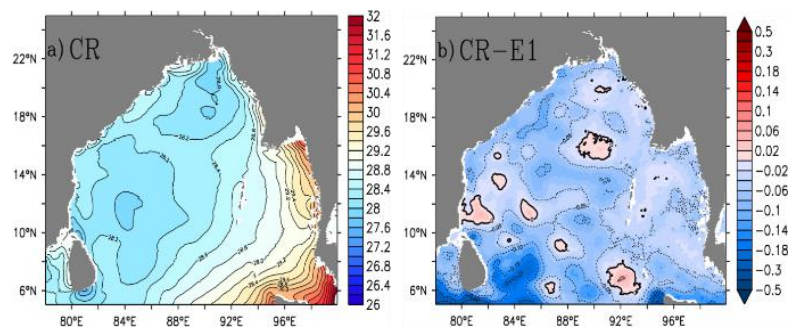

Figure 3. Time-mean sea surface temperature (SST, 0C) of (a) CR and the time-mean differences between (b) CR and E1 for the year 2015

The results above demonstrate that the feedback of model surface currents in the wind stress formulation dominates the differences in surface heat fluxes and the SST over the direct effect incorporating model surface currents in the heat flux calculation. As the differences are very small in magnitude, it is clear that the sudden response of surface heat flux is almost entirely governed by the relative wind component in the bulk formulation.

\subsection{Comparison with Satellite Observations}

Figure 4 shows the spatial map of RMSE between modelsimulated SST and GHRSST for the year 2015. It is clearly observed that the relative wind effect has actually minimized the SST error by around $\sim$ to $12 \%$ in the south-west BoB region. In the central $\mathrm{BoB}$, the errors have reduced by about $\sim 6 \%-8 \%$. When averaged over the entire $\mathrm{BoB}\left(5^{0}-25^{0} \mathrm{~N}\right.$, $78^{0} \mathrm{E}-100^{\circ} \mathrm{E}$ ), the mean SST error in $\mathrm{E} 1$ is about almost $2 \%$ lesser than those in CR. However, errors are quite large in both $\mathrm{CR}$ and $\mathrm{E} 1$ near the coastal regions for reasons that are not yet explored in this study. Both CR and E1 have higher correlation values in the head as well as in central bay (i.e., > 0.90, figure 5).

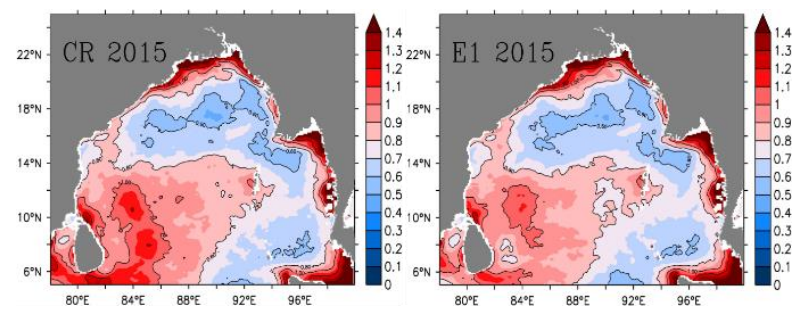

Figure 4. RMSE map of SST for CR and E1 with GHRSST for the year 2015

\subsection{Comparison with In-Situ Observations}

The vertical profiles of the domain-averaged $\left(5^{0}-\mathbf{2 5}^{0} \mathrm{~N}\right.$, $\mathbf{7 8}^{0} \mathrm{E}-\mathbf{1 0 0}^{\circ} \mathrm{E}$ ), temperature root mean square error (RMSE) between the experiments (i.e., CR and E1) and ARGO profiles are illustrated in Figure 5 (a). The two runs (E1 and CR) have similar, small cold biases near the sea surface. In the subsurface, in between $20-100 \mathrm{~m}$, error in temperature profile is increased by $0.5^{\circ} \mathrm{C}$, this may be due to decrease in wind stress magnitude that hinder the upper ocean vertical mixing and cause anomalous warming in the subsurface. At $100 \mathrm{~m}$ depth, the temperature error in $\mathrm{E} 1\left(\sim 1.7^{\circ} \mathrm{C}\right)$ is slightly less compared to $\mathrm{CR}\left(\sim 2.0^{\circ} \mathrm{C}\right)$. One can also see that at this depth the natural variability of temperature is more than the errors in the E1. The greatest differences occur at the depths ranging from $20 \mathrm{~m}$ to $100 \mathrm{~m}$. Correlation has significantly improved in the upper ocean in the E1 up to a depth of $10 \mathrm{~m}$. Figure 5 (b) represents the vertical profiles of root mean square error (RMSE) and correlation of simulated salinity from two different runs. The surface salinity error and correlation value in E1 is increased by $4 \%$ at this location as compared to CR. Below the surface, there is not much difference in salinity from $\mathrm{E} 1$ and $\mathrm{CR}$ at this location.
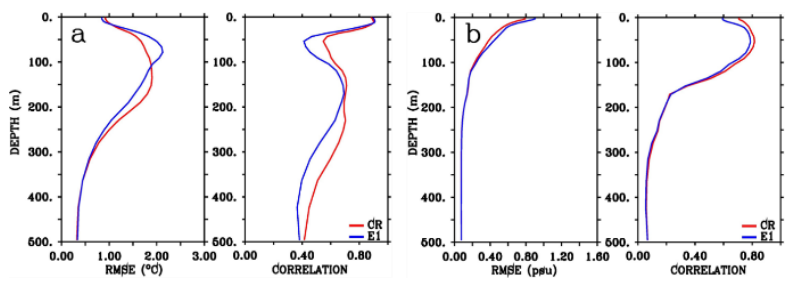

Figure 5. Vertical RMSE profile of simulated model a) Temperature and b) Salinity for the year 2015 for Bay of Bengal (BoB)

\section{CONCLUSION}

In this study, we have investigated the impact of including model surface currents in the bulk formulas on air-sea fluxes and the ocean general circulation model using a high resolution standalone TIO model. By comparing the model simulation that include and exclude model surface currents in air-sea flux formulation, we find changes in wind stress, heat flux and sea surface temperature are small when integrated over basin, but in some confined regions it alter by $\sim 10 \%-15 \%$ of the mean or even more. Wind stress is reduced over high wind zone region over the Bay of Bengal region, resulting in $\sim 10 \%$ reduction in the magnitude of coastal current. Heat flux to the atmosphere in the central Bay of Bengal reduced by $\sim 10 \%-15 \%$. We find in most of the Bay of Bengal region, SST increase when the relative wind stress effect is included, although the warming in our model is increased by $6 \%$. The model's increase in both Bay of Bengal SST and outgoing heat flux is interesting to note that increased heat flux to the atmosphere would tend to lower SST. It appears that including relative wind component in the heat flux formulas initially reduces heat flux out of the ocean, causing SST to warmer by $\sim 9 \%$. The warmer SST further opposes the relative wind stress effect, hence increasing the outgoing heat flux. The difference in wind stress on air-sea fluxes formulation in Bay of Bengal can significantly modify the upper ocean circulation pattern that affects the vertical mixing and the mixed layer depth (MLD). At the same time, though, that heating recharges the submerged warmer water that, when exposed by storms, may add additional thermal energy to storm growth. It is seen that although at several places the errors in SST have reduced by including the effect of ocean currents in the bulk formulae, there are still large errors in the model simulations in other regions. A different approach such as the one proposed by Fairall et al. 1994, 1996a, 1996b, 2003. to compute the exchange coefficients is required to be tested in the OGCM. 


\section{ACKNOWLEDGEMENTS}

Authors sincerely thank Director, Space Applications Centre, Deputy Director Earth, Ocean, Atmosphere, Planetary Sciences and Applications Area (EPSA) and Group Director, Atmospheric and oceanic sciences group, EPSA for constant support and encouragement. Figures were generated using the Ferret (NOAA/PMEL). Geophysical Fluid Dynamics Laboratory is thanked for providing the OGCM code. Diffused Attenuation Coefficient (Kd_490nm) data were obtained from $\mathrm{ftp}$ ://hermes.acri.fr/?class=archive. GHRSST date were downloaded from https://podaac.jpl.nasa.gov/GHRSST. Temperature and salinity profile data from GTSPP were available online at ftp://ftp.nodc.noaa.gov/pub/gtspp/indian/.

\section{REFERENCES}

Atlas R., 1987. The role of oceanic fluxes and initial data in the numerical prediction of an intense coastal storm. Dynamics of atmospheres and oceans, 10(4), 359-388, https://doi.org/10.1016/0377-0265(87)90025-X.

Atlas R., Busalacchi A. J., Ghil M., Bloom S., Kalnay E. 1987. Global surface wind and flux fields from model assimilation of Seasat data. Journal of Geophysical Research: Oceans, 92(C6), 6477-6487, https://doi.org/10.1029/JC092iC $06 \mathrm{p} 06477$.

Balmaseda M., Anderson D., Vidard A., 2007. Impact of Argo on analyses of the global ocean. Geophysical Research Letters, 34 (16), https://doi.org/10.1029/2007GL030452.

Barnier B., 1998. Forcing the ocean. In Ocean modeling and parameterization (pp. 45-80). Springer, Dordrecht, https://doi.org/10.1007/978-94-011-5096-5_2.

Berry D. I., Kent E. C., 2005. The effect of instrument exposure on marine air temperatures: An assessment using VOSClim data. International Journal of Climatology, 25(7), 1007-1022, https://doi.org/10.1002/joc.1178.

Blanc T. V., 1985. Variation of bulk-derived surface flux, stability, and roughness results due to the use of different transfer coefficient schemes. Journal of physical oceanography, 15(6), 650-669, https://doi.org/10.1175/15200485(1985)015\%3C0650:VOBDSF\%3E2.0.CO;2.

Blanc T. V., 1986. The effect of inaccuracies in weather-ship data on bulk-derived estimates of flux, stability and seasurface roughness. Journal of Atmospheric and Oceanic Technology, 3(1), 12-26, https://doi.org/10.1175/1520-0426 (1986)003\%3C0012:TEOIIW\%3E2.0.CO;2.

Blanc T. V., 1987. Accuracy of bulk-method-determined flux, stability, and sea surface roughness. Journal of Geophysical Research: Oceans, 92(C4), 3867-3876, https://doi.org/10.1029 /JC092iC04p03867.

Brodeau L., Barnier B., Gulev S. K., Woods C., 2017. Climatologically significant effects of some approximations in the bulk parameterizations of turbulent air-sea fluxes. Journal of Physical Oceanography, 47(1), 5-28, https://doi.org/10.1175/JPO-D-16-0169.1.
Brunke M. A., Fairall C. W., Zeng X., Eymard L., Curry J. A., 2003. Which bulk aerodynamic algorithms are least problematic in computing ocean surface turbulent fluxes? Journal of Climate, 16(4), 619-635, https://doi.org/10.1175/15200442(2003)016\%3C0619:WBAAAL\%3E2.0.CO;2.

Brunke M. A., Wang Z., Zeng X., Bosilovich M., \& Shie C. L., 2011. An assessment of the uncertainties in ocean surface turbulent fluxes in 11 reanalysis, satellite-derived, and combined global datasets. Journal of Climate, 24(21), 54695493, https://doi.org/10.1175/2011JCLI4223.1.

Brunke M. A., Zeng X., Anderson S., 2002. Uncertainties in sea surface turbulent flux algorithms and data sets. Journal of Geophysical Research: Oceans, 107(C10), 5-1, https://doi.org/10.1029/2001JC000992.

Cabanes C., Grouazel A., Schuckmann K. V., Hamon M., Turpin V., Coatanoan C., ..., Boyer Montegut C. D., 2013. The CORA dataset: validation and diagnostics of in-situ ocean temperature and salinity measurements. Ocean Science, 9(1), 1-18, https://doi.org/10.5194/os-9-1-2013.

Chen D., Busalacchi A. J., \& Rothstein L. M., 1994. The roles of vertical mixing, solar radiation, and wind stress in a model simulation of the sea surface temperature seasonal cycle in the tropical Pacific Ocean. Journal of Geophysical Research: Oceans, 99(C10), 20345-20359, https://doi.org/10.1029/94JC01621.

Chen, S., Flatau, M., Jensen, T. G., Shinoda, T., Schmidt, J., May, P., ..., Lien R. C., 2015. A study of CINDY/DYNAMO MJO suppressed phase. Journal of the Atmospheric Sciences, 72(10), 3755-3779, https://doi.org/10.1175/JAS-D13-0348.1.

Cumming, J. A., Szczechowski C., Carnes M., 1997. Global and regional ocean thermal analysis systems. Marine Technology Society. Marine Technology Society Journal, 31(1), 63.

Da Silva A. M., 1994. Algorithms and Procedures. Vol. 1, Atlas of Surface Marine Data. NOAA Atlas NESDIS, 6, 74.

Dawe J. T., Thompson L., 2006. Effect of ocean surface currents on wind stress, heat flux, and wind power input to the ocean. Geophysical research letters, 33(9), https://doi.org/10.1029/2006GL025784.

Dee D. P., Uppala S. M., Simmons A. J., Berrisford P., Poli P., Kobayashi S., ..., Bechtold P., 2011. The ERA-Interim reanalysis: Configuration and performance of the data assimilation system. Quarterly Journal of the royal meteorological society, 137(656), 553-597, https://doi.org/10.1002/qj.828.

Donlon C. Casey K. Minnett P., Corlett G., 2014. The Group for High Resolution Sea Surface Temperature: Past, Present and Future. In EGU General Assembly Conference Abstracts (Vol. 16).

Duhaut T. H., Straub D. N., 2006. Wind stress dependence on ocean surface velocity: Implications for mechanical energy input to ocean circulation. Journal of physical 
oceanography, 36(2), 202-211, https://doi.org/10.1175/JPO28 42.1 .

Eden C., Dietze H., 2009. Effects of mesoscale eddy/wind interactions on biological new production and eddy kinetic energy. Journal of Geophysical Research: Oceans, 114(C5), https://doi.org/10.1029/2008JC005129.

Edson J. B., Jampana V., Weller R. A., Bigorre S. P., Plueddemann A. J., Fairal C. W., ..., Hersbach H., 2013. On the exchange of momentum over the open ocean. Journal of Physical Oceanography, 43(8), 1589-1610.

\section{Erik Anderson (Version 1.2, 2011) ECMWF: User guide}

Eymard L., Caniaux G., Dupuis H., Prieur L., Giordani H., Troadec R., ..., Guérin C., 1999. Surface fluxes in the North Atlantic current during CATCH/FASTEX. Quarterly Journal of the Royal Meteorological Society, 125(561), 3563-3599, https://doi.org/10.1002/qj.49712556121.

Fairall C. W., Bradley E. F., Godfrey J. S., Wick G. A., Edson J. B., Young G. S., 1996a. Cool-skin and warm-layer effects on sea surface temperature. Journal of Geophysical Research: Oceans, 101(C1), 1295-1308, https://doi.org/10.1029/95JC0 3190.

Fairall C. W., Bradley E. F., Hare J. E., Grachev A. A., Edson J. B., 2003. Bulk parameterization of air-sea fluxes: Updates and verification for the COARE algorithm. Journal of climate, 16(4), 571-591, https://doi.org/10.1175/15200442(2003)016\%3C0571:BPOASF\%3E2.0.CO;2.

Fairall C. W., Bradley E. F., Rogers D. P., Edson. B., Young G. S., 1996b. Bulk parameterization of air-sea fluxes for tropical ocean-global atmosphere coupled-ocean atmosphere response experiment. Journal of Geophysical Research: Oceans, 101(C2), 3747-3764, https://doi.org/10.1029/95JC03205.

Fairall C. W., Kepert J. D., Holland G. J., 1994. The effect of sea spray on surface energy transports over the ocean. Global Atmos. Ocean Syst, 2(2-3), 121-142.

Gill A., 1982. Atmospheric-ocean dynamics. Int. Geophys. Ser., 30, 662.

Hogan T. F., Rosmond T. E., 1991. The description of the Navy Operational Global Atmospheric Prediction System's spectral forecast model. Monthly Weather Review, 119(8), 1786-1815, https://doi.org/10.1175/15200493(1991)119\%3C1786:TDOTNO\%3E2.0.CO;2.

Hughes C. W., Wilson C., 2008. Wind work on the geostrophic ocean circulation: An observational study of the effect of small scales in the wind stress. Journal of Geophysical Research: Oceans, 113(C2), https://doi.org/10.1029/2007JC004371.

Jensen T. G., Shulman I., Wijesekera H. W., Anderson S., Ladner S., 2018. Submesoscale features and their interaction with fronts and internal tides in a high-resolution coupled atmosphere-ocean-wave model of the Bay of Bengal. Ocean Dynamics, 68(3), 391-410, https://doi.org/10.1007/s10236018-1136-x.
Jensen T. G., Wijesekera H. W., Nyadjro E. S., Thoppil P. G., Shriver J. F., Sandeep K. K., \& Pant V., 2016. Modeling salinity exchanges between the equatorial Indian Ocean and the Bay of Bengal. Oceanography, 29(2), 92-101.

Jerlov N., 1968. Optical Oceanography. Elsevier Oceanography Series, 5.

Josey S. A., Kent E. C., Taylor P. K., 1999. New insights into the ocean heat budget closure problem from analysis of the SOC air-sea flux climatology. Journal of Climate, 12(9), 2856-2880, https://doi.org/10.1175/15200442(1999)012\%3C2856:NIITOH\%3E2.0.CO;2.

Josey S. A., Yu L., Gulev S., Jin X., Tilinina N., Barnier B., \& Brodeau L., 2014. Unexpected impacts of the Tropical Pacific array on reanalysis surface meteorology and heat fluxes. Geophysical Research Letters, 41(17), 6213-6220, https://doi.org/10.1002/2014GL061302.

Kallberg P., 1998. ECMWF Re-Analysis Project Report Series: Aspects of the Re-analysed Climate. European Centre for Medium-Range Weather Forecasts.

Kara A. B., Rochford P. A., Hurlburt H. E., 2000. Efficient and accurate bulk parameterizations of air-sea fluxes for use in general circulation models. Journal of Atmospheric and Oceanic Technology, 17(10), 1421-1438.

Large W. G., Pond S., 1982. Sensible and latent heat flux measurements over the ocean. Journal of physical Oceanography, 12(5), 464-482.

Large W. G., McWilliams J. C., Doney S. C., 1994. Oceanic vertical mixing: A review and a model with a nonlocal boundary layer parameterization. Reviews of Geophysics, 32(4), 363-403, https://doi.org/10.1029/94RG01872.

Lee Z. P., Du K. P., Arnone R., 2005. A model for the diffuse attenuation coefficient of downwelling irradiance. Journal of Geophysical Research: Oceans, 110 (C2), https://doi.org/10.1029/2004JC002275.

Levitus S., 1982. Climatological atlas of the world ocean. NOAA Prof. Paper 13. Washington, DC: US Government Printing Office.

Luo J. J., Masson S., Roeckner E., Madec G., Yamagata T., 2005. Reducing climatology bias in an ocean-atmosphere CGCM with improved coupling physics. Journal of climate, 18(13), https://doi.org/10.1175/JCLI3404.1.

McCreary J. P., Kundu P. K., Molinari R. L., 1993. A numerical investigation of dynamics, thermodynamics and mixed-layer processes in the Indian Ocean. Progress in Oceanography, 31(3), 181-244, https://doi.org/10.1016/00796611(93)90002-U.

Munday D. R., Zhai X., 2015. Sensitivity of Southern Ocean circulation to wind stress changes: Role of relative wind stress. Ocean Modelling, 95, 15-24, https://doi.org/10.1016/j.ocemod.2015.08.004. 
Pacanowski R. C., 1987. Effect of equatorial currents on surface stress. Journal of physical oceanography, 17(6), 833838.

Pacanowski R. C., Griffies S. M., 1999. The MOM 3 manual, alpha version. NOAA. Geophysical Fluid Dynamics Laboratory.

Papa F., Prigent C., Aires F., Jimenez C., Rossow W. B., Matthews E., 2010. Interannual variability of surface water extent at the global scale, 1993-2004. Journal of Geophysical Research: https://doi.org/10.1029/2009JD012674

Paulson C. A., Simpson J. J., 1977. Irradiance measurements in the upper ocean. Journal of Physical Oceanography, 7(6), 952-956, https://doi.org/10.1175/15200485(1977)007\%3C0952:IMITUO\%3E2.0.CO;2.

Price J. F., Weller R. A., Bowers C. M., Briscoe M. G., 1987. Diurnal response of sea surface temperature observed at the long-term upper ocean study $\left(34^{\circ} \mathrm{N}, 70^{\circ} \mathrm{W}\right)$ in the Sargasso Sea. Journal of Geophysical Research: Oceans, 92(C13), 14480-14490, https://doi.org/10.1029/JC092iC13p14480.

Rath W., Greatbatch R. J., Zhai X., 2013. Reduction of nearinertial energy through the dependence of wind stress on the ocean-surface velocity. Journal of Geophysical Research: Oceans, 118(6),

https://doi.org/10.1002/jgrc.20198.

Scott R. B., Xu Y., 2009. An update on the wind power input to the surface geostrophic flow of the World Ocean. Deep Sea Research Part I: Oceanographic Research Papers, 56(3), 295304, https://doi.org/10.1016/j.dsr.2008.09.010.

Shinoda T., Jensen T. G., Flatau M., Chen S., 2013. Surface wind and upper-ocean variability associated with the MaddenJulian oscillation simulated by the Coupled OceanAtmosphere Mesoscale Prediction System (COAMPS). Monthly Weather Review, 141(7), 2290-2307, https://doi.org/10.1175/MWR-D-12-00273.1.

Shriver J. F., Hurlburt H. E., 1997. The contribution of the global thermohaline circulation to the Pacific to Indian Ocean through flow via Indonesia. Journal of Geophysical Research: Oceans, 102(C3),

https://doi.org/10.1029/96JC03602. 5491-5511,

Siedler G., Griffies S. M., Gould J., Church J. A., 2013. Ocean circulation and climate: a 21st century perspective (Vol. 103). Academic Press.

Sun C., Thresher A., Keeley R., Hall N., Hamilton M., Chinn P., Cowen L., 2010. The data management system for the global temperature and salinity profile programme. Proceedings of OceanObs, 9.

Swenson M. S., Hansen D. V., 1999. Tropical Pacific Ocean mixed layer heat budget: The Pacific cold tongue. Journal of Physical Oceanography, 29(1), 69-81, https://doi.org/10.1175/1520-

0485(1999)029\%3C0069:TPOMLH\%3E2.0.CO;2.

Vorosmarty C. J., Fekete B. M., Tucker B. A., 1998. Global River Discharge, 1807-1991, V. 1.1 (RivDIS). ORNL DAAC, Oak Ridge, Tennessee, USA.

Weller R. A., Baumgartner M. F., Josey S. A., Fischer A. S., Kindle J. C., 1998. Atmospheric forcing in the Arabian Sea during 1994-1995: Observations and comparisons with climatology and models. Deep Sea Research Part II: Topical Studies in Oceanography, 45(10-11), 1961-1999, https://doi.org/10.1016/S0967-0645(98)00060-5.

Xu C., Zhai X., Shang X. D., 2016. Work done by atmospheric winds on mesoscale ocean eddies. Geophysical Research Letters, 43(23), https://doi.org/10.1002/2016GL071275.

Xu Y., Scott R. B., 2008. Subtleties in forcing eddy resolving ocean models with satellite wind data. Ocean Modelling, 20(3), 240-251, https://doi.org/10.1016/j.ocemod.2007.09.003.

Yuen C. W., Cherniawsky J. Y., Lin C. A., Mysak L. A., 1992. An upper ocean general circulation model for climate studies: Global simulation with seasonal cycle. Climate dynamics, 7(1), 1-18, https://doi.org/10.1007/BF00204817.

Zeng X., Zhao M., Dickinson R. E., 1998. Intercomparison of bulk aerodynamic algorithms for the computation of sea surface fluxes using TOGA COARE and TAO data. Journal of Climate, 11(10), 2628-2644, https://doi.org/10.1175/15200442(1998)011\%3C2628:IOBAAF\%3E2.0.CO;2.

Zhai X., Greatbatch R. J., 2007. Wind work in a model of the northwest Atlantic Ocean. Geophysical research letters, 34(4), https://doi.org/10.1029/2006GL028907.

Zhai X., Johnson H. L., Marshall D. P., Wunsch C., 2012. On the wind power input to the ocean general circulation. Journal of Physical Oceanography, 42(8), 1357-1365, https://doi.org/10.1175/JPO-D-12-09.1.

Zhang G. J., McFarlane N. A., 1995. Sensitivity of climate simulations to the parameterization of cumulus convection in the Canadian Climate Centre general circulation model. Atmosphere-ocean, 33(3), 407-446, https://doi.org/10.1080/07055900.1995.9649539. 